\title{
The Role of Dynamic Networks in Social Capital: A Simulation Experiment
}

\author{
Sandra González Bailón \\ University of Oxford. Nuffield College \\ sandra.gonzalezbailon@nuffield.ox.ac.uk
}

\begin{abstract}
This paper has two basic aims: the first is to understand why networks matter in the creation and maintenance of social capital; the second is to explore many of the (unproved) assumptions that arise when social capital is applied to the field of political participation. A simulation-based experiment is used to achieve both aims. The paper starts by delimiting the scope of the theoretical problem. It then reviews the assumptions made in the literature about the role networks play for social capital, and integrates them with what is known about dynamic networks. The third section provides a brief introduction to the methodological nature of simulation. It justifies the appropriateness of this technique to tackle the questions posed by the existing theory. A description of the simulation model and its results follows. The first set of experiments explores the structural properties of different networks in respect of information diffusion. The second set analyses a principle of action that might be responsible for the formation of social capital networks. The implications that these results have for the theory are assessed in the conclusion. Their links to future research are also discussed.
\end{abstract}

Key words: social capital, networks, political participation, multi-agent simulation.

Resumen. El papel de la redes dinámicas en el capital social: un experimento de simulación

El objetivo de este artículo es doble: por un lado, entender por qué importan las redes en la creación y mantenimiento de capital social y, por otro, explorar muchas de las asunciones (no probadas) que surgen cuando el concepto de capital social se aplica al campo de la participación política. Ambos objetivos se llevan a cabo con la ayuda de un experimento de simulación. El artículo empieza exponiendo los términos del problema teórico. Prosigue con un resumen de las asunciones que aparecen en la literatura sobre el rol que las redes juegan en el funcionamiento del capital social y las contrasta con lo que se sabe acerca del funcionamiento de redes dinámicas. La tercera sección proporciona una breve introducción a la naturaleza metodológica de la simulación multi-agente. Le sigue una descripción del modelo de simulación y de sus resultados. El primer conjunto de experimentos explora las propiedades estructurales de distintas redes respecto a la difusión de información. El segundo conjunto analiza un principio de acción responsable de la formación de redes de capital social. Las implicaciones teóricas de estos resultados son valoradas en la conclusión. También se discuten futuras líneas de investigación.

Palabras clave: capital social, redes, participación política, simulación multi-agente. 


\section{Contents}

$\begin{aligned} \text { 1. Introduction: the Problem } & \text { 4. The Simulation Experiment } \\ \text { 2. The Assumptions: the Impact } & \text { 5. Conclusions } \\ \text { of Networks on Political Participation } & \text { 6. Further Research } \\ \text { 3. The Methodology of Simulation } & \text { References }\end{aligned}$

\section{Introduction: the Problem}

Theories of social capital have long stressed the importance of interpersonal networks. These provide people with non-economic resources (status, recognition, trust, information) from which they can benefit whilst simultaneously advantaging the community as a whole. Investing in social relations pays in the form of rewards, real or potential, that individuals can obtain from their networks in a diversity of markets: educational (Coleman 1988), labour (Lin and Dumin 1986), economic (Portes 1993) and political (Putnam 1995). Social ties allow the flow of information and resources, and they are thus valuable both as a stock of support and as transmission channels. They are also the raw material of reciprocity and trust: these can only be maintained when interactions take place in sufficiently dense networks, that is, when it becomes possible to monitor individuals' reputation. Social capital is thus a unique mixture of structure and content (Degenne and Forsé 1999, p. 116), a concept that aims to capture the nature of social interactions through which, paraphrasing Mandeville, private vices can become public benefits. It is in the field of political participation that this twofold dimension finds a highly relevant example. The idea that social capital promotes democratic virtue and civic engagement, popularised by Putnam a decade ago (Putnam 1995; Putnam 2000; Putnam et al. 1993), has become a common place in sociology.

Yet there is no agreed explanation about why interpersonal networks are powerful in the creation of social capital, let alone in the promotion of democracy. Many authors claim network density and closure are fundamental, but this denies the significance of other features like bridges, structural holes and weak ties (Lin 2001, p. 27). On the other hand, there is some analytical evidence against the idea that dense networks of interaction lead to a reduction of opportunism: when transmitting information, these can actually increase free-riding (Lazer 2003). This paper aims to shed light on the role that the structural dimension of social capital plays by answering the following questions: why, and to what extent, are dynamic networks an important aspect of social capital? And what can we learn about the behavioural rules underlying the emergence of social capital networks? Social simulation opens the experimental framework within which to explore the implications that different rules of interaction have for the emerging structures. These can then be empirically tested in order to narrow down the range of possible (and plausible) mecha- 
nisms. The simulation model presented below is a first step towards this systematic analysis.

\section{The Assumptions: the Impact of Networks on Political Participation}

Social capital theory highlights the importance of social ties for the information and resources they can bring to individuals. When applied to the political context, social capital theory also emphasises how important social ties are for the rules of conduct they help to promote (Herreros 2000). Networks are assumed to have positive externalities that go beyond the benefits individuals pursue: they promote norms of generalised reciprocity and the emergence of trust, they facilitate coordination and communication, they contribute to the spread of political expertise, they reduce opportunism and foster collaboration and they enhance the participant's "taste» for collective benefits (Putnam 2000, p. 20-22). The level of connectedness of networks is alleged to "aid in the maintenance of democracy by ensuring that political participation is tolerant, moderate and publicly oriented» (Paxton 1999, p. 102). The basic assumption is that, for a variety of reasons, entangled individuals are more inclined towards the public good than isolated ones.

However, neither Putnam nor his disciples manage to give an explanation of how and why all these processes take place: their approach to networks, based on proxies such as group membership, gives them an insufficient base to sustain their argument. The number and type of groups membership are used to estimate the general level of associations and these, in turn, to estimate the overall density of civic networks (Paxton 1999, p. 101). But there is no census of ties within and between associations, so the theoretical assumptions about the role networks play are based on a measure of network that does not resemble a network at all. Putnam and his disciples cannot prove that social capital ties have good political consequences because their approach to networks is simply misleading. All they can show is a correlation between membership and political action with no structural component.

This weakness is actually one of the consequences of a wider methodological problem: the absence of a satisfactory causal theory of the relationship between social capital and observed behavioural patterns (Durlauf 2002). In his approach, Putnam "fails to account for the ways in which phenomena such as levels of trust in a society are endogenous outcomes of social relations» (Ibid., p. 263). This lack of causal mechanism results in conceptual ambiguity and compels a purely exogenous treatment of social capital. When social capital is treated exogenously, the theory becomes just another instance of cultural explanation: subjective orientations are arbitrarily considered more important than the objective conditions in which they arise (Jackman and Miller 1998). Building a theory on this assumption is problematic in itself. But it is especially problematic when applied to the analysis of social capital, that is, to the operationalisation of a concept that was explicitly intended to capture the importance of the structure in which individuals are embedded. 


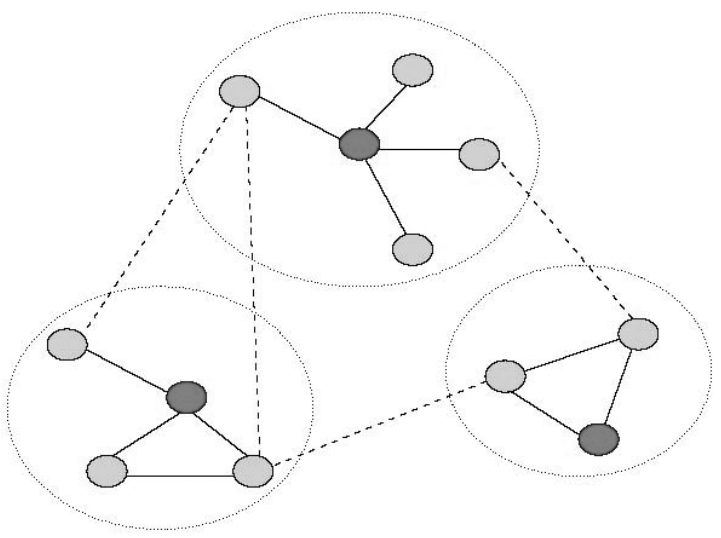

Figure 1. Ego centric networks embedded in an unknown global structure

Others have tried to approach the network dimension of social capital more systematically (La Due Lake and Huckfeldt 1998). In these approaches, the US Cross National Election Project from 1992 is used to provide information about 1286 personal networks. These networks consist of up to five discussants with whom respondents talked about important matters, including politics. The results show that political engagement is a function of the size of the network, the political expertise of its members and the frequency of interaction between them. Those individuals with larger networks, with higher levels of expertise and greater frequency of interactions report participation in a wider variety of political activities. Thesse include working for a party or candidate, attending meetings, displaying political signs, donating money or simply voting. The article suffers, though, from two interrelated flaws: one involves the theory; the other concerns the data.

First: This interpretation assumes that networks of social relations are responsible for the transmission of political information and expertise (Ibid., p. 570). Networks are said to serve the fundamental purpose of decreasing the information costs associated with political participation and therefore of promoting it. Yet there is no explanation of why: it is assumed without further discussion that networks facilitate the flow of information whatever their structure. What is more, the study does not provide information about a global structure: it is based on data about ego centric networks, that is, about networks that are isolated from each other (see figure 1). And second: respondents were allowed to name less than five discussants, but not more. Real personal networks might thus be richer than what the study shows. The approach to networks is here more explicit, but there is still no proper structural component to verify (or falsify) the background assumptions.

Traditional network analysis, on the other hand, takes into account the full importance of network structural properties to the transmission of infor- 


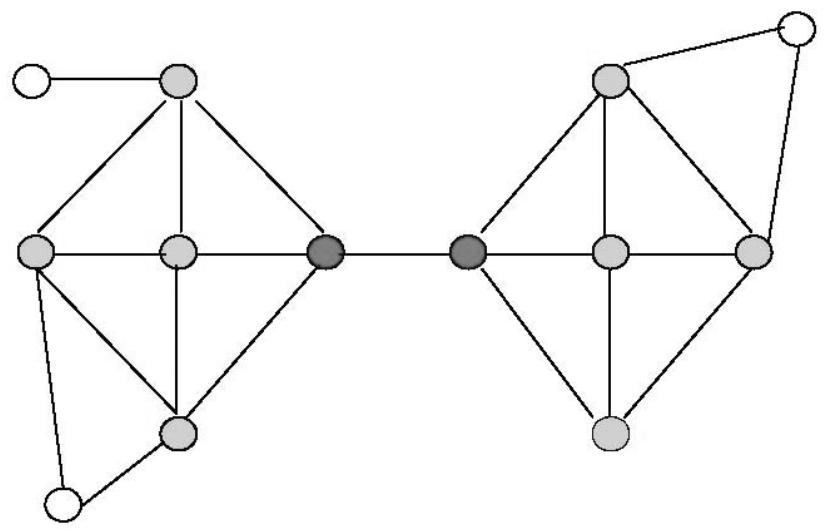

Figure 2. The importance of positions within a global network structure

mation and resources. This approach stresses the relevance of the distinct positions that individuals hold in the global network, a structural location that gives them a more or less privileged access to resources. As figure 2 shows, some individuals (here represented with dark nodes) are in a much better position than others, despite having the same number of ties. Networks can provide individuals with two types of competitive advantage: one through closure and one through brokerage (Burt 2000). In the first type, the advantage comes from the management of risk: closed networks enhance communication and facilitate the enforcement of sanctions. In the second type, the advantage comes from information access and control: networks with structural holes allow some individuals to control information flow between two segments of the network that would otherwise be isolated.

That structure matters is one of the core claims of social capital research. However, Granovetter, Milgram and Coleman all discovered, long before the social capital literature emerged, significant properties of social networks topology: their classic "weak ties», "six degrees» and innovation diffusion studies make clear how important structure is for the dynamics that take place on a network (Coleman et al. 1957; Granovetter 1973; Milgram 1967). Still they had little to say about the mechanisms underlying those processes. In traditional network analysis agents are not given the opportunity to interact and change the structure they are occupying through their interactions. The extent to which cooperation and reciprocity contribute to creating the structure of the network is something these studies do not consider. Yet, both cooperation and reciprocity are assumed to be basic building blocks for the construction of politically relevant social capital.

More concerned with dynamic networks than with social capital, a number of studies have provided analytical evidence about how the topology of networks relates to the processes that take place within them (Barabási 2002; 
Buchanan 2002; Strogatz 2003; Watts 2001; Watts 1999). In this literature, some social networks are found to be scale free and to have "small world» properties. Scale free networks are networks without a characteristic scale in their connectivity: they do not have an average node because their degree distribution does not follow a bell curve (most nodes having the same number of links) but a power law (where there are very many nodes with only a few links and a few hubs with a large number). Small world networks are networks that (following Milgram's research) make it possible to connect a node with any other node in the network in only a few steps. Scale free networks also show some interesting properties: they are a «cheaper» means to get the small world phenomena (they require fewer ties to attain the six degrees of separation) and they are more robust to failures (less likely to be disrupted by broken ties). How fast and efficiently information and resources spread will therefore depend on these network structural properties. Whether social capital networks reproduce them is, again, something that remains untested.

Some authors have explored the impact of networks in the emergence of norms and conventions (Delgado 2002; Lazer 2003; Stocker et al. 2001; Stocker et al. 2002). Others have considered a range of possible mechanisms underlying the emergence of dynamic networks (Conte et al. 1998; Hummon 2000; Skyrms and Pemantle 2000). But the implications these findings have for social capital research have not yet been explored. We do not yet know whether politically relevant social networks are scale free. We also cannot demonstrate that they are «small world» due to a lack of data about the global structure of civic communities. The existing research, though, suggests some facts about social capital networks: we know that individuals are influenced in their political engagement by the characteristics of those that surround them (La Due Lake and Huckfeldt 1998); we know that weak ties serve individuals' goals while linking a diversity of interests that would otherwise be unrelated (Boissevain 1978); and we know that failure to build those ties has negative political consequences, such as the loss of common experience and a consequent fragmentation of society (Sunstein 2001). A simulation experiment can help us build a deeper insight and thus lead to substantive developments in theory and focussed data collection.

\section{The Methodology of Simulation}

In order to overcome the methodological limitations of traditional approaches to social capital discussed above, this paper makes use of simulation, a computer-based modelling strategy that allows experimentation with dynamic networks (González 2004). A multi-agent system is built in order to test, first, the structural properties of different networks and their relative efficiency in the diffusion of information; and, second, a principle of action that could underlie the emergence of social capital networks.

Multi-agent systems (MAS) are systems in which agents are distributed in an artificial environment and are able to interact with each other and/or with the 
environment in a parallel fashion (Gilbert and Troitzsch 1999). Despite their generality and diverse applications, there are four basic characteristics that define a MAS: their compromise with methodological individualism; their ability to model 'invisible hand' processes; their assumption of bounded rationality in agent interactions; and their ability to capture emergent, counter-intuitive processes.

The first characteristic, their compromise with methodological individualism, makes MAS especially concerned with micro dynamics of agent interactions: they are given priority over the macro level, which is assumed to derive from them. In MAS most of the activities are performed by agents who interact with each other and display heterogeneous rules of behaviour (Epstein and Axtell 1996, p. 4). Social structures and group dynamics emerge from the interaction of agents which only process local information. This approach is related to the second characteristic of MAS: their ability to model «invisible hand» dynamics where information is not processed globally by a central authority but locally by a swarm of interacting units. MAS are especially well suited to analyse complexity, that is, those patterns of global behaviour difficult to predict mathematically because large numbers of actors with changing patterns of interaction are involved in the process (Axelrod 1997, p. 3). Since social capital is usually treated as an example of spontaneous order, the use of MAS is a natural framework for its analysis.

The third characteristic of MAS is their assumption of bounded rationality in agent interactions. MAS make it possible to construct models where individual agents apply heuristic strategies to make effective use of their imperfect knowledge (Gilbert and Doran 1994). The rationale behind individual investment in social relations is empirically closer to the situation of bounded rationality than to the omniscient nature imputed to economic agents. This technique has advantages over other approaches such as rational choice theory. Analysing the conditions under which trust and cooperation (the building blocks of social capital) emerge is one of the objectives of game theory. But the only structural constraints game theoretical models take into account are those which can be expressed in terms of payoffs. MAS allow the introduction of more realistic environments that impose structural constraints on individual choices. Finally, MAS are characterised by their ability to capture emergent, counterintuitive processes. Emergence is associated with complex systems, dense networks of interactions and non-linearity, that is, with those features that make it difficult to predict the evolution of a system (Holland 1998, p. 225-231). A classical example of emergence can be found in Schelling's segregation models (Schelling 1969; Schelling 1971; Schelling, 1978): agents do not seek segregation in their local interactions, but the system finds its equilibrium in a segregated state.

All of these properties make MAS particularly well suited to the analysis of social capital networks. But, above all, they make MAS well suited to the search for explanatory causes: this strategy «moves away from a correlative approach — based on quantitative variables - and towards a processual approach based on social mechanisms» (Chattoe 2000, p. 1). Most of the research on social capital, oriented towards statistical models based on aggregated vari- 
ables, is simply not able to detect and analyse those mechanisms. And without mechanisms, social capital assumptions become a petitio principii, that is, a fallacy where conclusions are taken for granted in the premises.

\section{The Simulation Experiment}

This simulation experiment is a preliminary approach to understanding the dynamics underlying social capital. In particular, its aim is to test the assumptions made in the literature about how networks benefit democracy. These assumptions can be summarised in the following terms:

(i) External effects:

i. Networks allow political information flow (Paxton 1999; Putnam 1995; Putnam 2000).

ii. Networks reduce information costs (La Due Lake and Huckfeldt 1998). (ii) Internal effects:

i. Networks promote cooperation and "public spiritedness» (Paxton 1999; Putnam 1995; Putnam 2000).

ii. Networks contribute to spreading the practical skills necessary to take part in public life (La Due Lake and Huckfeldt 1998; Verba et al. 1995).

In these assumptions, voluntary associations and the consequent network dimension of social capital are said to contribute to democracy in two different ways: "they have 'external' effects on the larger polity, and they have 'internal' effects on participants themselves. Externally (...) political information flows through social networks, and in these networks public life is discussed (...) Internally (...) networks of civic engagement instil in their members habits of cooperation and public spiritedness, as well as the practical skills necessary to partake in public life» (Putnam 2000, p. 338). The first type of effect deals with the structure of networks; the second, with their content.

Underlying this, there is another assumption: that «an individual's informal friendships with old schoolmates, fellow workers, or the friend of a friend can create social capital through increased communication, information diffusion, and social support» (Paxton 1999, p. 100). The connectedness of the overall network is assumed to enrich information flow and, with this, the pool of ideas and interests that have to be publicly defended. Networks are said to contribute to the existence of a forum where everybody has the chance to spread their views. They are also assumed to warrant lower information costs and, therefore, greater political engagement: "politically relevant social capital should enhance the likelihood of individual engagement in politics, enabling citizens to become engaged in ways they might otherwise not» (La Due Lake and Huckfeldt 1998, p. 570).

This external dimension is complemented by its internal effects. Networks are said to promote information diffusion and political participation, but also trustworthiness and cooperation: «Dense social ties facilitate gossip and other valuable ways of cultivating reputation» (Putnam 2000, p. 21). Networks facil- 
itate the acquisition of practical skills necessary to take an active part in public life (Verba et al. 1995, p. 304). In this literature, it is not only "civic virtues» that matter, but also other technical (and more mundane) skills such as learning how to value and assess arguments, how to work out opinions or how to develop ideas. Social capital, to sum up, is alleged to benefit democracy by educating its citizens, by putting them together and making them learn from each other. In other words, the core assumption in the literature is that social capital "serves to enhance human capital on the cheap» (La Due Lake and Huckfeldt 1998, p. 581). The experiments that follow are an attempt to delimit the extent to which networks can be made responsible of these effects.

\subsection{The Model: Network Structure}

This set of experiments has a twofold aim: to illustrate why the structure of networks is important for the processes they hold, and to show how simulation can contribute to bridge the gaps that undermine the empirical data. In so doing, simulation brings into focus the kind of data that should be collected to make empirical research more informative. It also uncovers theoretical flaws that would go unnoticed otherwise. The experiments are based on the data provided by La Due Lake (1998) and on the scale free networks research. The results show that there is more to diffusion effects than just the density of networks: the distribution of ties, and its impact in the overall structure, also plays a significant role in the efficiency of the diffusion process.

The starting point of the simulation is, thus, the distribution of personal networks provided by the 1992 Cross National Election Project (Ibid.). For computational reasons, the number of agents with political discussants was reduced by a factor of 10 , but the distribution is based on the same percentages. Table 1 shows the number of agents in the model with the corresponding number of political discussants.

As mentioned above, to test the theoretical assumptions of social capital we need a global structure, not just 127 isolated ego networks. The easiest way to put these personal networks together is to establish random links between the agents. Three possible scenarios are tested: one in which only hubs can be

Table 1. Personal Network Size of Agents (hubs).

\begin{tabular}{|c|c|c|}
\hline Number of Political Discussants (alters) & Freq & $\%$ \\
\hline 0 & 11 & 8.4 \\
\hline 1 & 22 & 17.4 \\
\hline 2 & 20 & 15.4 \\
\hline 3 & 24 & 18.7 \\
\hline 4 & 23 & 18.4 \\
\hline 5 & 27 & 21.7 \\
\hline Total & 127 & 100.00 \\
\hline
\end{tabular}




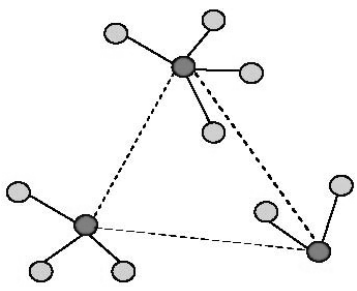

Scenario 1: hubs with hubs

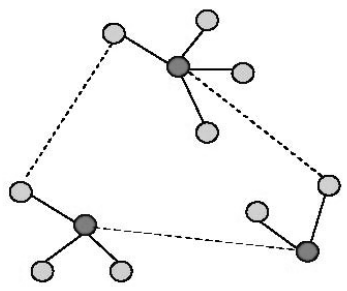

Scenario 2: all with all

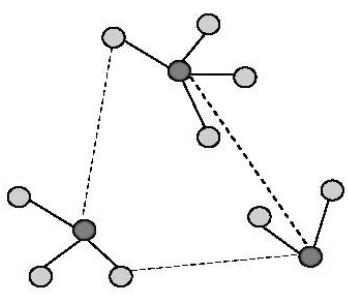

Scenario 3: hubs with all

Figure 3. Three Rules to Establish Weak Ties.

randomly linked, one in which all agents can be randomly linked, and one in which only hubs can be linked but this time with any other agent.

The structural properties of the emerging networks are quantified, following Watts and Strogatz (1998), by their average path length and clustering coefficients. The average path length is the number of edges in the shortest path between two agents. This coefficient measures how far away an agent is from any other agent in the network. The clustering coefficient is the mean of the clustering coefficient of all actors, which measures the density of their neighbourhood. This coefficient measures the extent to which someone's friends are also each others friends. Finally, the third coefficient, density, measures the number of existing ties divided by the total number of possible ties. In order to obtain these coefficients, the simulated networks were exported to UCINET. The results for the three scenarios are summarised in table 2 .

The number of weak ties each agent is allowed to have is a parameter in the range from 1 to 5: the more weak ties, the more access to other groups, and therefore, to information and diversity. The results are intuitive: a network where all agents are allowed to establish weak ties with any other agent has a higher density and, consequently, a shorter average distance between any pair of nodes. In this simulated network of nearly 500 agents - the 127 hubs and their respective discussants - allowing one weak tie per agent (independent of their position) results in each agent being only seven steps away from every other in the global network.

Some tentative conclusions can be drawn from these results: promoting casual encounters (the basis for weak ties), and doing so regardless of the characteristics of individuals, brings people closer. This is indeed the baseline for better democracies: having access to a wide array of people makes it possible to consider issues that would otherwise be ignored and, therefore, to revise views in the light of what is learned. The promotion of casual encounters (the promotion of weak ties) guarantees general access to heterogeneous citizens, and also a shared exposure to diverse views and experiences. Both are necessary conditions to maintain a deliberative democracy (Sunstein 2001, p. 30-31), 
Table 2. Network Properties for the Three Scenarios.

\begin{tabular}{|c|c|c|c|c|c|c|c|c|c|}
\hline \multirow{2}{*}{$\begin{array}{l}\text { Number of } \\
\text { Weak Ties }\end{array}$} & \multicolumn{3}{|c|}{ Density } & \multicolumn{3}{|c|}{$\begin{array}{c}\text { Distance } \\
\text { (average path length) }\end{array}$} & \multicolumn{3}{|c|}{$\begin{array}{c}\text { Clustering Coefficient } \\
\text { (cliquishness) }\end{array}$} \\
\hline & S1 & S2 & S3 & $\mathrm{S} 1$ & S2 & S3 & S1 & S2 & S3 \\
\hline 1 & 0.0036 & 0.0051 & 0.0036 & $8.025^{*}$ & $7.236^{*}$ & $12.059^{*}$ & 0.000 & 0.003 & 0.006 \\
\hline 2 & 0.0041 & 0.0072 & 0.0041 & $7.141^{*}$ & $5.013^{*}$ & $11.501^{*}$ & 0.002 & 0.006 & 0.000 \\
\hline 3 & 0.0047 & 0.0092 & 0.0047 & $5.618^{*}$ & $4.214^{*}$ & $7.379^{*}$ & 0.013 & 0.010 & 0.002 \\
\hline 4 & 0.0052 & 0.0114 & 0.0052 & $4.921^{*}$ & 3.758 & $6.407^{*}$ & 0.013 & 0.012 & 0.006 \\
\hline 5 & 0.0057 & 0.0134 & 0.0057 & 4.566 & 3.476 & $5.745^{*}$ & 0.019 & 0.012 & 0.005 \\
\hline
\end{tabular}

* among reachable pairs.

Table 3. Random Distribution of Ties in Scenario 2.

\begin{tabular}{lccc}
\hline $\begin{array}{c}\text { Number of } \\
\text { Weak Ties }\end{array}$ & Density & $\begin{array}{c}\text { Distance } \\
\text { (average path length) }\end{array}$ & $\begin{array}{c}\text { Clustering Coefficient } \\
\text { (cliquishness) }\end{array}$ \\
\hline Up to 5 & 0.0081 & $4.775^{*}$ & 0.010 \\
Up to 6 & 0.0093 & $4.332^{*}$ & 0.010 \\
Up to 7 & 0.0102 & $4.147^{*}$ & 0.011 \\
Up to 8 & 0.0113 & $3.895^{*}$ & 0.012 \\
Up to 9 & 0.0128 & 3.662 & 0.015 \\
\hline
\end{tabular}

* among reachable pairs.

which is not far from Putnam's claims about the importance of associationism for a better democracy.

But assuming that all agents have the same number of weak ties also means assuming that they can spend the same amount of time and effort in building them, which is not very realistic. So another simulation was run for scenario 2 (the one that is intuitively closer to a civic network in a democratic society) distributing the number of weak ties randomly. The results are shown in table 3.

This time, each agent can have between 0 and $\mathrm{n}$ weak ties (where $\mathrm{n}$ is set as a parameter), linking them to any other agents in the same network. When the maximum is set to five, something interesting happens: with up to five weak ties (additional to the strong ties distributed at the initialisation), agents build a network with the same structural properties, in terms of distance and cliquishness, as the network that emerged giving each agent three weak ties. In other words: with less density (with fewer ties), the same cliquishness and nearly the same path distance are obtained. A network with up to five weak ties per agent is «cheaper» than a network in which every agent is given three of them because fewer ties are needed. But since the path length is very similar, it is equally efficient when transmitting information: the number of edges a piece of news has to cross to reach any two agents in the network is almost the same. 


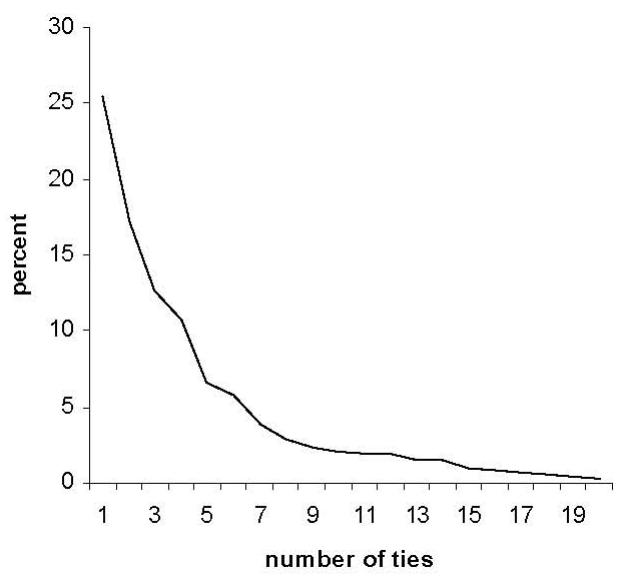

Figure 4. Power Law Distribution of Ties.

The validation (or falsification) of these properties with real networks would help to resolve their empirical relevance, but such data is not available. Still these results allow the examination of Putnam's theoretical conclusions in a different light. He might be right when he points out that a decrease in the level of associationism brings a parallel decrease in the density of civic networks. Yet he might go too far when he concludes that less density also means less efficiency: the distribution of ties also contributes to the production of efficiency, a contribution that Putnam ignores. A lower density does not necessarily mean that civic networks do not accomplish their function of spreading political information any more. They might be accomplishing it even better if the right number of individuals have the right number of connections. The link between level of associationism, networks, and democracy is not as straightforward as social capital literature assumes.

How are weak ties distributed in the simulation? Since the distribution of ties is random, agents get them more or less evenly: the proportion of agents with one weak tie is, roughly, the same as the proportion of agents with two, three, four or five weak ties. Yet, according to some research (Barabási 2002), the distribution of ties in social networks follows a power law distribution, which can be seen in figure 4 .

To work with this distribution we must make an assumption about the size of the tail. In order to experiment with the power law distribution, three other simulations were run. Table 4 shows the results.

What these experiments show is that even with lower density (that is, with fewer ties), we can get a very similar average path distance and clustering coefficient to that which occurs when agents have more ties each. The message is, again, that what matters is not how much individuals are connected but rather 
Table 4. Power-Law Distribution of Ties in Scenario 2.

\begin{tabular}{|c|c|c|c|c|}
\hline $\begin{array}{c}\text { Agents with } \\
<4 \\
\text { Weak Ties }\end{array}$ & $\begin{array}{c}\text { Agents with } \\
>15 \\
\text { Weak Ties }\end{array}$ & Density & $\begin{array}{c}\text { Distance } \\
\text { (average } \\
\text { path length) }\end{array}$ & $\begin{array}{c}\text { Clustering } \\
\text { Coefficient } \\
\text { (cliquishness) }\end{array}$ \\
\hline $55 \%$ & $4 \%$ & 0.0122 & 3.794 & 0.014 \\
\hline $75 \%$ & $2 \%$ & 0.0099 & 4.213 & 0.014 \\
\hline $90 \%$ & $1 \%$ & 0.0079 & $4.854^{*}$ & 0.010 \\
\hline
\end{tabular}

* among reachable pairs.

how a particular number of individuals manage to connect the rest. This is actually what the small world phenomena is about: «it means that a very small number of people are linked to everyone else in a few steps, and the rest of us are linked to the world through those special few» (Gladwell 2001, p. 37). These highly connected individuals have an influence disproportionate to their number (Watts 2003, p. 105). But given that information is a public good, these "aristocratic» (Buchanan 2002, p. 161) networks turn out to be beneficial for everybody.

Why are these findings important? Because the dynamics that take place on networks depend on their structure. And their structure determines whether the alleged effects of social capital are true or not. So far it has been shown that a higher density does not necessarily translate into better network conditions for the flow of political information or the spread of resources. In order to give additional illustration, and to test how structure affects dynamics, a very simple diffusion process is introduced into the simulation. Agents are given an attribute that models a political idea with two possible values: 0 or 1 . The first could stand for "The Government knew Irak had WMD" ${ }^{1}$, and the second could stand for «The Government made up the whole story about the WMD». Agents are initialised with the attribute value 0 , and only one of them, chosen randomly, has attribute value 1 . This agent can then transmit the idea to the agents linked to it, independently of the strength of their ties. Every time step, agents with idea 1 do the same with their contacts, and so on until the diffusion stops.

This process is simulated in scenario 2 under the three different weak ties distributions explored above. The results of the diffusion are shown in figure 5 .

The slope of the curves during the initial time steps is largely a result of the personal network of the introducing agent. But the tendencies are clear: the "up to five» network allows the idea to reach everybody at the same time as the network where all agents have three weak ties. In other words: a network with lower density obtains the same results, and the same efficien$c y$, as a network with more ties. In the power-law network with an even smaller density, the diffusion process takes a bit longer —one additional

1. Weapons for Massive Destruction. 

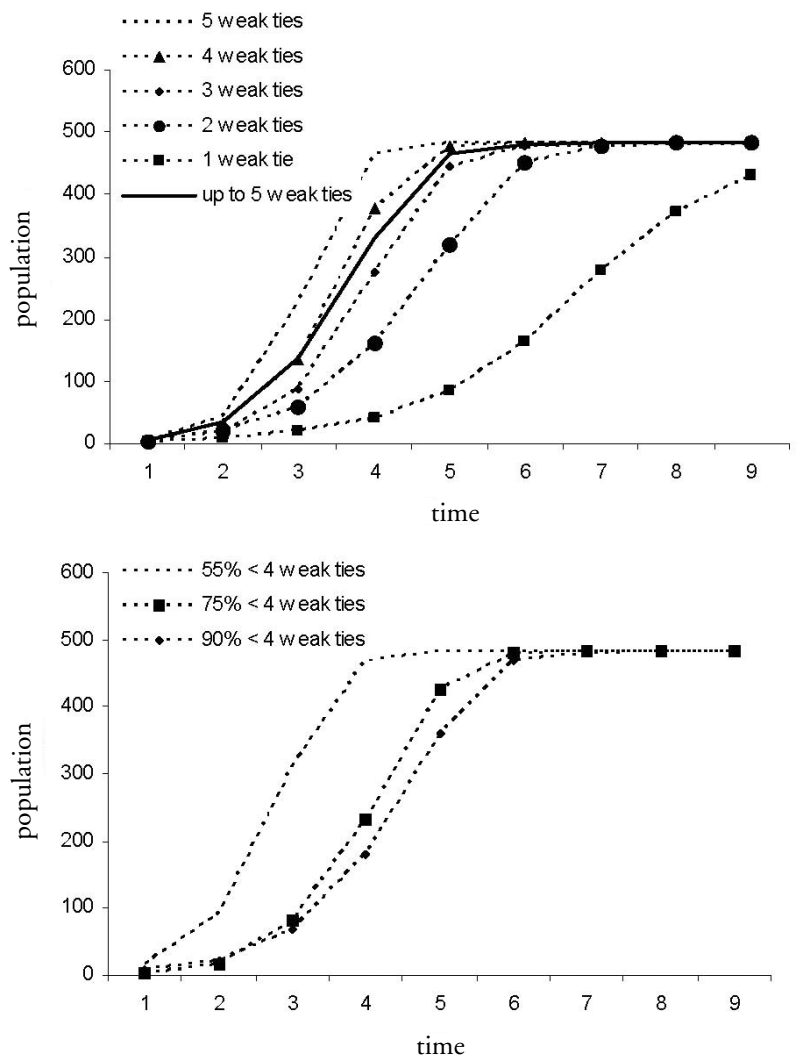

Figure 5. Diffusion Process in Scenario 2.

time step of the simulation. But this structure also spreads the idea to the whole population.

Is it true then that networks allow political information flow (Putnam 1995; Putnam 2000) and contribute to spread the practical skills necessary to take part in public life (La Due Lake and Huckfeldt 1998)? The simulation presented above is too simple to determine with detail how the flow of information and the spread of skills take place. But it does prove that networks facilitate these processes under certain circumstances that cannot be simply reduced to the level of associationism and the consequent density of networks. As Putnam claims, there might be a relationship between the number of associations individuals belong to and the density of their civic networks. But the relationship between the density and the efficiency of networks is, regardless of the theory, far from obvious. To ground Putnam's claims, explicit data about the distribution of ties is needed — data that do not currently exist. 


\subsection{The model: agent behaviour}

The experiments that form this section are another attempt to overcome the lack of empirical data, this time by being more explicit about the dynamics of social capital networks. This part of the simulation does not treat networks as fixed but as emerging structures that result from agents interactions. Again, the starting point of the simulation are La Due Lake (1988) findings: their analysis show that the larger the personal network of individuals, the more expertise of its members, and the greater the frequency of interactions between them, the more participation individuals have in political activities. The simulation assumes that as political participation increases, the potential number of weak ties is likely to increase as well. The programme models this by giving every agent a level of political engagement that determines their number of possible weak ties: the higher the level of engagement, the higher the chances of having weak ties. The rationale behind this assumption is intuitive: an individual that takes active part in the political campaign of a candidate will have a larger network of (politically-relevant) acquaintances than an individual whose engagement is reduced to voting during the elections day. In order to measure the level of expertise of personal networks, agents are given a level of education and a level of knowledge about politics. The level of education is distributed randomly when the model is initialised, but strong contacts share, by default, the same education level. The level of knowledge about politics is a random number with a maximum equal to the level of education of every agent. This means that while the level of education is the same for agents and their strong contacts, their knowledge about politics might differ substantially.

In order to measure the content dimension of social capital (as opposed to the structural dimension captured by networks), agents are given two additional attributes: a stock of support and a stock of information. The stock of support is a function of the size of the agent strong contacts network (the more friends, the more support) and of the frequency of interactions (the more interactions, the more cooperation). The stock of information is a function of the size of the agent weak contacts (an empty list when the model is initialised) and of the weak contacts' level of knowledge about politics. The model assumes that networks of strong contacts are redundant in the information they process, and thus that only weak ties are sources of new information. Weak ties are also interpreted as the bridges of shared experience that prevent the fragmentation of ideas and knowledge, the "social glue» that join citizens together (Sunstein 2001 , ch. 4). Figure 6 summarises the logic behind the introduction of these attributes.

In every time step, agents have to decide whether to interact with one of their strong contacts or to establish a (weak) tie with a new acquaintance. Agents have limited time to invest in social relations so they have to choose between interacting with existing strong ties and establishing new weak ones. When an agent decides to establish a new weak tie, the dismissed strong contact increases a memory of interactions refused by one. When that memory reaches 


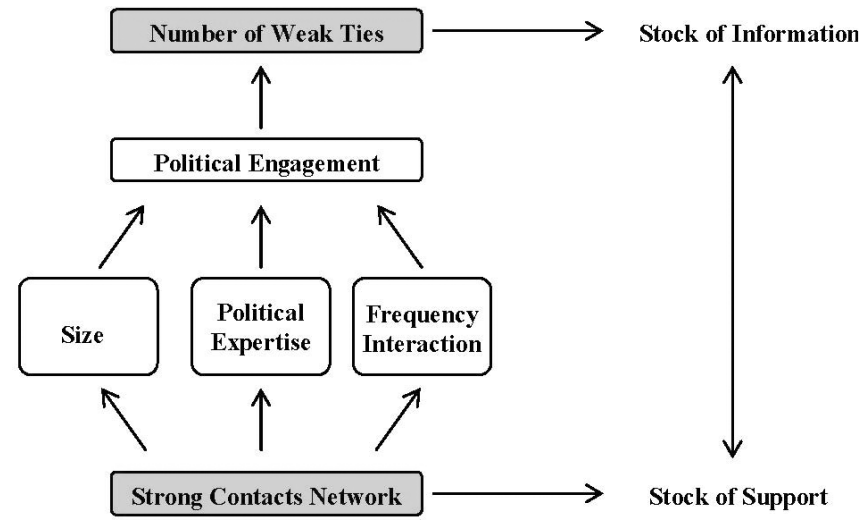

Figure 6. Agent Attributes.

a threshold, strong contacts send an alarm message: if another interaction is refused, they will drop their tie. The threshold is a parameter that measures the "strength" of strong ties. In this simulation, the parameter is given the same value as the frequency of interactions. If a strong contact has a frequency of interactions of 3 (e.g. they meet 3 times per week), and has been refused 3 consecutive times, it will set the alarm on. When this happens, agents have to decide whether to keep the strong contact or to add instead a new weak contact to their network.

Different decision rules can be modelled to solve this choice. The rule used in this simulation tries to capture the principle of minimization of loss and maximization of gain: "Given the opportunity, actions are taken to fulfil both motives. However, when the actor must make a choice, preference is given to maintaining resources: the higher priority is given to the calculation that minimizes loss» (Lin 2001, p.131). Since minimizing loss has priority over maximizing gain, agents will choose to interact with the strong partner whatever the net contribution to their stock of social capital. The impact of this decision rule in the distribution of ties can be seen in table 5 .

The mean of weak ties per hub stays between three and four across the runs. But as the variance reveals, the distribution is quite scattered. Figure 7 shows that, indeed, the number of agents with three or fewer ties is much higher than the number of agents with more than four ties for all the simulation runs.

The reason why the number of agents with more than four weak ties is so small lies in the constraints of the model. The number of potential weak ties an agent can build depends on its political engagement. And to have a high political engagement, three circumstances have to be met: (i) a large network of strong contacts; (ii) a high level of political expertise in the network of strong contacts; and (iii) a high level of interaction. Agents that meet these three cri- 
Table 5. Distribution of Ties following the Minimum Loss Principle.

\begin{tabular}{cccccc}
\hline & \multicolumn{5}{c}{ Weak Ties } \\
\cline { 2 - 6 } Simulation Run & Mean & Range & Min & Max & Variance \\
\hline $\mathbf{1}$ & 4.04 & 9 & 1 & 10 & 6.562 \\
2 & 3.50 & 8 & 1 & 9 & 4.839 \\
3 & 3.17 & 9 & 1 & 10 & 4.488 \\
$\mathbf{4}$ & 3.77 & 10 & 1 & 11 & 5.586 \\
5 & 3.65 & 8 & 1 & 9 & 4.990 \\
$\mathbf{6}$ & 3.50 & 8 & 1 & 9 & 4.823 \\
7 & 3.64 & 8 & 1 & 9 & 5.407 \\
8 & 3.56 & 9 & 1 & 10 & 5.629 \\
9 & 3.89 & 9 & 1 & 10 & 5.305 \\
$\mathbf{1 0}$ & 3.53 & 9 & 1 & 10 & 4.775 \\
\hline
\end{tabular}

teria are scarce. Agents with a high number of weak ties are, therefore, scarce as well. But it is not only the level of political engagement what matters. How 'demanding' strong contacts are is also an important variable in the equation: agents have to satisfy their calls for interaction, and while they do that, they cannot invest their time in building weak ties.

In order to compare the structural differences between a network emerging from the principle of minimising loss and a network created randomly, another simulation is run in scenario 3 (see page 180). In that simulation, and in order to allow a comparison with the last simulation from table 5, hubs can build up to a maximum of 10 weak ties. The results of the comparison are shown in table 6 .

The random network has a higher density and a shorter average path length than the minimisation-of-loss network. This is a consequence of the indiscriminate distribution of ties that underlies the emergence of random networks.

The minimisation-of-loss network has a distribution of ties that fits better with the rich-get-richer effect of scale-free networks discussed above. It also captures the intuition behind Pareto's 80-20 rule: that a small fraction of people always own a large fraction of the wealth (Barabási 2002; Buchanan 2002).

Table 6. 'Minimisation of Loss' Network vs Random Network.

\begin{tabular}{lccc}
\hline & Density & $\begin{array}{c}\text { Distance } \\
\text { (average path length) }\end{array}$ & $\begin{array}{c}\text { Clustering Coefficient } \\
\text { (cliquishness) }\end{array}$ \\
\hline Random & 0.0058 & $6.187^{*}$ & 0.009 \\
Minimisation Loss & 0.0049 & $7.144^{*}$ & 0.008 \\
\hline
\end{tabular}

* among reachable pairs. 

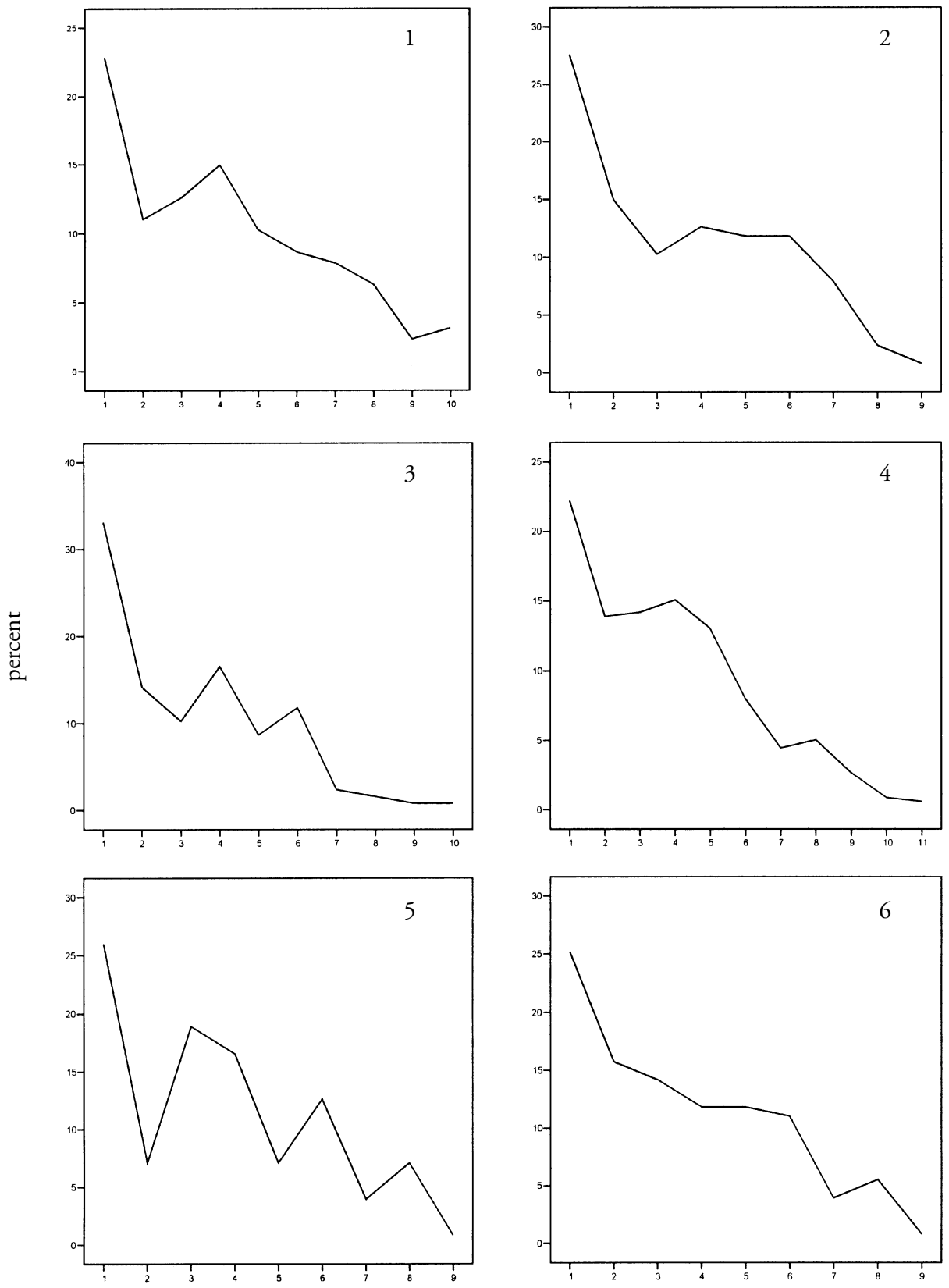

number of ties

Figure 7. Distribution of Weak Ties in each Simulation. 


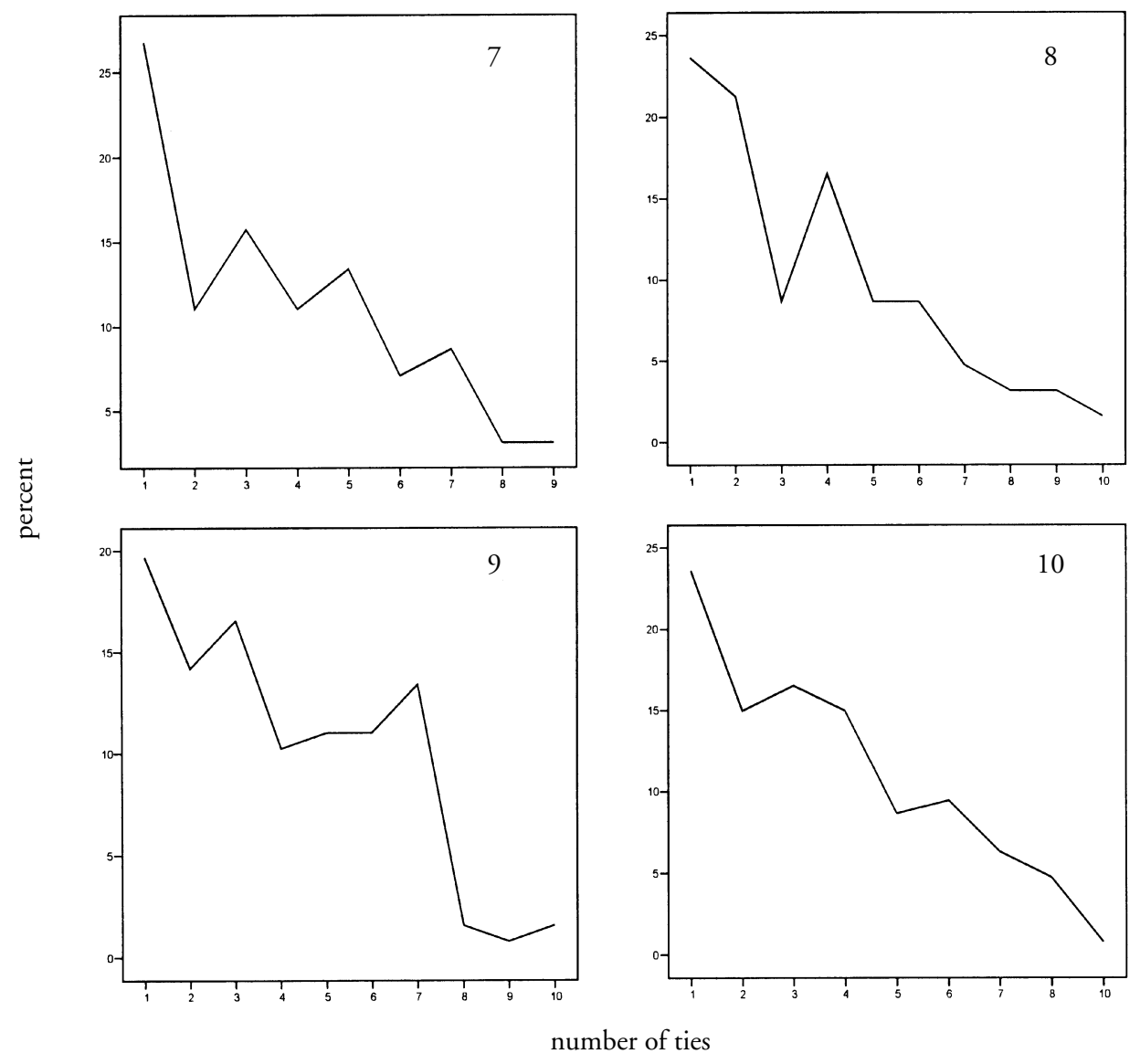

Figure 7. Distribution of Weak Ties in each Simulation (continuation).

However, the distribution turns out to be more a result of the function that defines the political engagement of agents than of the decision rule: it is a matter of time that all of them can achieve their maximum number of weak ties. Agents have to be surrounded by very exigent strong contacts not to be able to turn their potential number of weak ties into real acquaintances.

What can we learn from this simulation? In the first place, that social capital networks might display the same properties as the networks explored in the previous section. Now, though, we have a behavioural rule that could be explored empirically in order to allow further predictions about real networks. The simulation also reinforces the idea that it is not only density that matters: the distribution of connections plays an important role as well. If the right number of individuals have the right number of connections, information can 


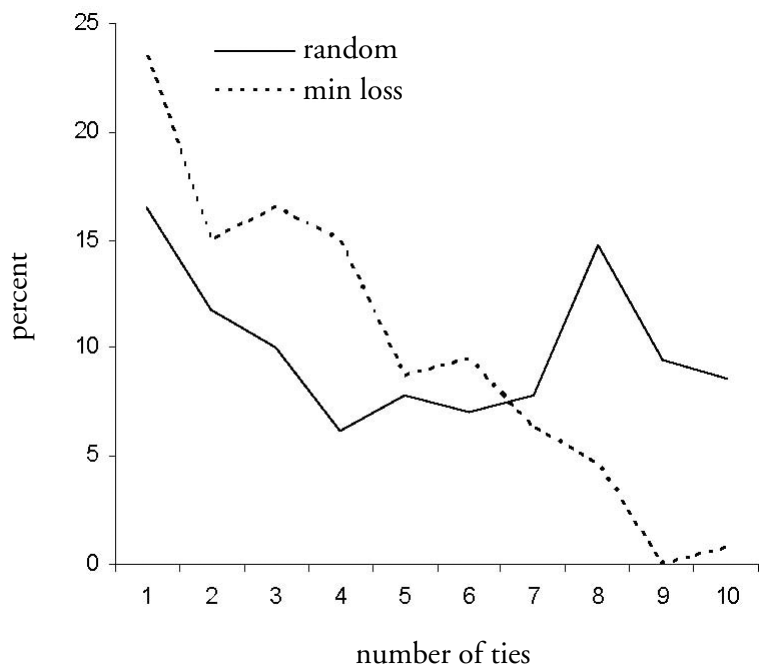

Figure 8. Distribution of Ties for Networks in Table 6.

spread as fast as it can in networks with higher densities. This could also be the case for social capital networks, which means that the more efficient they are in the diffusion of information, the lower the information costs for all individuals. That is the compensation everybody gets for the 'aristocratic' nature of scale-free networks: since information is a public good, when one person gets to know something, others will benefit as well (Sunstein 2001, p. 99), especially when the structure of the network promotes wide spread and rapid diffusion.

Yet these results also open way to a rather different kind of interpretation. As information diffuses more efficiently, it becomes more of a public good. And as the publicness of information increases, so does the likelihood of free riding (Lazer 2003). In other words: there is an incentive for each individual to let others pay the costs of getting information. The public goods aspect of social capital was already remarked by Coleman in the late 80 s (Coleman 1988). Whether Coleman is right and social capital overcomes the cooperation problem by becoming a sub-product of other actions is a question that remains open and that can only be assessed by introducing cooperation games in the simulation. For the purposes of this paper, though, the simulation results are clear: linking social capital networks to the promotion of cooperation is, at best, an assumption that lacks an unambiguous foundation. 


\section{Conclusions}

Social capital literature assumes that networks promote the diffusion of information and skills, enhance cooperative behaviour, and reduce information costs. Yet when applied to the field of political participation, the only units available to measure networks are the number and type of associations individuals belong to, or fragments of networks that tell us very little about the overall structure. With that information it is simply impossible to assess whether the theoretical assumptions on the role networks play are founded or just a way of begging the question. Given the lack of empirical data, this paper used social simulation to create networks with different topological characteristics. The experiments test the impact these different properties have on the processes networks hold.

The first basic finding is that the density of networks is not a necessary condition for their efficiency in the diffusion of information or resources. While it is true that the more ties a network has, the closer individuals are of each other, it is also true that the same effect can be obtained when the right number of individuals has the right number of ties - even if the network density is lower. The second basic finding is that social capital networks could, indeed, reproduce the scale free distribution of ties and, therefore, be especially efficient in the diffusion of information or resources. A corollary of this, though, is that the lower the costs of information are, the higher the chances of getting free-riding behaviour. As access to information opens up, information becomes more of a public good. And with public goods, there is always the risk of slipping into the tragedy of the Commons: it is tempting for each individual to let other individuals pay the costs of getting information; it is easy to forget that they might be doing the same; and so, in the long run, it is inevitable for everybody to lose their share.

Social capital theory still has to explain how networks promote cooperation at the same time that they promote an efficient information diffusion. It has to differentiate between density and efficiency, and between efficiency in the transmission of information and efficiency in the promotion of cooperation. Finally, when the outcome under analysis is democracy and political participation, a third distinction is needed: a normative definition of efficiency has to be clearly delimited to compare it with the technical definition. A network where all nodes are exclusively connected to a central node is highly efficient, but it is closer to Orwell's totalitarian society than to a civic community. Different network designs can be equally effective in diffusing information or resources, but designs do not contain information about the good or evil of their implementation. A normative criterion is necessary to define «efficiency» when applied to the role networks play in the field of political participation.

Social capital assumptions are intuitively right, but in the detail, the theory is full of misunderstandings and ambiguities about how networks work. It is by paying attention to these details that a theory becomes robust and informative. Simulation contributes to this analytical aim in two ways: it can delimit areas 
where there is an absence of empirical information, and it can design research strategies able to bridge those gaps and find, at least, conceptual inconsistencies. Even when the data is not yet available, simulation assumptions are always susceptible of empirical validation and therefore of being tested when the right information is gathered. It can actually help to determine what kind of empirical information should be gathered. As opposed to what happens in most sociological research, simulation allows a deductive approach to social capital.

\section{Further Research}

The simulation model presented here has two general limitations: the first, methodological, results from an insufficient sensitivity analysis to the assumptions. A thorough statistical analysis of the simulation outputs is needed to determine if they are significant or rather the effect of an accidental initialisation. The second limitation is empirical, and it refers to the absence of data that allow the calibration of the model. The simulation assumptions would be less arbitrary if richer data on real networks and their distribution of ties were available. The ideal for future research would be to collect data using social network methods, but individuals' actual level of association could also be used to root the distribution of weak ties. This would allow a deeper insight into the scope of Putnam's theory and his claim about the importance of associationism for better democracies.

The simulation can also be extended to try to address some of the unanswered questions: the trade-off between the benefits that strong and weak contacts bring can be reformulated to allow the decision rule to have a more significant impact on the emerging network. Other decision rules can be incorporated to enrich the range of plausible mechanisms underlying the formation and maintenance of social capital networks. Individuals can be modelled as normative agents that pursue cooperation unconditionally or as daring investors that give priority to their new connections. Different strategies to solve cooperation dilemmas would also allow a more methodical exploration of the tension between the public nature of information and individuals' cooperative behaviour. Overall, these extensions could contribute to developing the conceptualization of social capital and exploring the causal mechanisms that are currently ignored.

\section{References}

Axelrod, R. (1997). The Complexity of Cooperation. Agent-based Models of Competition and Collaboration. Princeton, NJ: Princeton University Press.

BarabÁSI, A.L. (2002). Linked. The New Science of Networks. Cambridge, MA: Perseus. BoISSEVAIN, J. (1978). Friends of Friends. Networks, manipulators and coalitions. Oxford: Basil Blackwell.

Borgatti, S.P.; EveretT, M.G.; FreEMAN, L.C. (2002). Ucinet 6 for Windows. Harvard, MA: Analytic Technologies. 
BUCHANAN, M. (2002). Nexus: small worlds and the groundbreaking science of networks. New York, NY: W.W. Norton.

BURT, R.S. (2000). «The Network Structure of Social Capital». In: SUTTON, R.I; STAW, B.M. (eds.). Research in Organizational Behaviour. Greenwich: JAI Press.

Chattoe, E. (2000). «Why Is Building Multi-Agent Models of Social Systems So Difficult? A Case Study of Innovation Diffusion». Paper presented at the XXIV International Conference of Agricultural Economists (IAAE), Mini-Symposium on «Integrating Approaches for Natural Resource Management and Policy Analysis: Bioeconomic Models, Multi-Agent Systems and Cellular Automata", Berlin, 1319 August.

Coleman, J.S. (1988). "Social Capital in the Creation of Human Capital». American Journal of Sociology, vol. 94, p. S95-S120.

Coleman, J.S.; MenZel, H.; KATZ, E. (1957). «The diffusion of an innovation among physicians». Sociometry, vol. 20, p. 253-270.

Conte, R.; Castelfranchi, C.; Veneziano, V. (1998). «The Computer Simulation of Partnership Formation». Computational and Mathematical Organization Theory, vol. 4, p. 293-315.

Degenne, A.; Forsé, M. (1999). Introducing Social Networks. London: Sage.

Delgado, J. (2002). «Emergence of Social Conventions in Complex Networks». Artificial Intelligence, vol. 141, p. 171-185.

DURLAUF, S.N. (2002). «Bowling Alone: a Review Essay». Journal of Economic Behaviour and Organization, vol. 47, p. 259-273.

Epstein, J.M.; AXTELl, R. (1996). Growing Artificial Societies. Social Science from the Bottom Up. Cambridge, MA: MIT Press.

GILBERT, N.; DORAN, J. (1994). «Simulating Societies: an introduction». In: GILBERT, N.; Doran, J. (eds.). Simulating Societies. The computer simulation of social phenomena. London: UCL Press.

Gilbert, N.; Troitzsch, K.G. (1999). Simulation for the Social Scientist. Buckingham: Open University Press.

Gladwell, M. (2001). The Tipping Point. How little things can make a big difference. London: Abacus.

GONZÁLEZ BAILÓN, S. (2004). «¿Sociedades Artificiales? Una introducción a la simulación social». Revista Internacional de Sociología, vol. 39, p. 199-222.

GranovetTER, M. (1973). «The strength of weak ties». American Journal of Sociology, vol. 78, p. 1360-1380.

Herreros, F. (2000). «Social Capital, Associations, and Civic Republicanism». In SaWARD, M. (ed.). Democratic Innovation: Deliberation, Representation and Associations. London: Routledge.

Holland, J.H. (1998). Emergence. From chaos to order. Oxford: Oxford University Press.

Hummon, N.P. (2000). «Utility and Dynamic Social Networks». Social Networks, vol. 22, p. 221-249.

JaCKMAN, R.W.; Miller, R.A. (1998). «Social Capital and Politics». Annual Review of Political Science, vol. 1, p. 47-73.

La Due LaKe, R.; Huckfeldt, R. (1998). «Social Capital, Social Networks, and Political Participation». Political Psychology, vol. 19, p. 567-584.

LAZER, D. (2003). «Information and Innovation in a Networked World». In: BREIGER, R.; Carley, K.; PatTison, P. (eds.). Dynamic Social Network Modeling and Analysis: Workshop Summary and Papers. Washington, DC: National Academies Press. 
Lin, N. (2001). Social Capital. A theory of social structure and action. Cambridge: Cambridge University Press.

Lin, N.; Dumin, M. (1986). «Access to Occupations Through Social Ties». Social Networks, vol. 8, p. 365-385.

Milgram, S. (1967). «The Small World problem». Psychology Today, vol. 2, p. 60-67. PAXTon, P. (1999). «Is Social Capital Declining in the United States? A Multiple Indicator Assessment». American Journal of Sociology, vol. 105, p. 88-127.

PORTES, A. (1993). «Social Capital: its Origins and Applications in Modern Sociology». Annual Review of Sociology, vol. 24, p. 1-24.

PutNAM, R.D. (1995). «Bowling Alone: America’s Declining Social Capital». Journal of Democracy, vol. 6, p. 65-78.

- (2000). Bowling Alone. The collapse and revival of American community. New York: Simon and Schuster.

Putnam, R.D.; LeOnardi, R.; NANeTtI, R.Y. (1993). Making Democracy Work: civic traditions in modern Italy. Princeton, NJ: Princeton University Press.

Schelling, T.C. (1969). «Models of Segregation». The American Economic Review, vol. LIX, p. 488-493.

- (1971). «Dynamic Models of Segregation». Journal of Mathematical Sociology, vol. 1, p. 143-186.

- (1978). Micromotives and Macrobehavior. London: Norton.

Skyrms, B.; Pemantle, R. (2000). «A Dynamic Model of Social Network Formation». Proceedings of the National Academy of Sciences, vol. 16, p. 9340-9346.

STOCKER, R.; CORNFORTH, D.; Bossomaier, T.R.J. (2002), «Network Structures and Agreement in Social Network Simulations». Journal of Artificial Societies and Social Simulation, vol. 5. http://jass.soc.surrey.ac.uk/5/4/3.html

Stocker, R.; Green, D.G.; Newth, D. (2001). "Consensus and Cohesion in Simulated Social Networks». Journal of Artificial Societies and Social Simulation, vol. 4. http://soc.surrey.ac.uk/JASSS/4/4/5.html

STROGATZ, S.H. (2003). SYNC: the emerging science of spontaneous order. New York, NY: Theia.

Sunstein, C. (2001). Republic.com. Princeton, NJ: Princeton University Press.

Verba, S.; Schlozman, K.L.; Brady, H.E. (1995). Voice and Equality: Civic Voluntarism in American Politics. Cambridge, MA: Harvard University Press.

WatTs, A. (2001). «A Dynamic Model of Network Formation». Games and Economic Behaviour, vol. 34, p. 331-341.

WatTs, D.J. (1999). Small Worlds. The Dynamics of Networks between Order and Randomness. Princeton, NJ: Princeton University Press.

- (2003). Six Degrees. The Science of a Connected Age. London: William Heinemann.

WATTS, D.J.; STROGATZ, S.H. (1998). "Collective dynamics of »small world» networks». Nature, vol. 393, p. 440-442.

WILENSKY, U. (1999). NetLogo, http://ccl.northwestern.edu/netlogo. Evanston, IL.: Center for Connected Learning and Computer-Based Modeling, Northwestern University. 